\title{
Study of e-smile service influence on customers' satisfaction in social business context
}

\author{
He Weijun ${ }^{1}$ - Wang Hui ${ }^{1}$ - Lin Ling ${ }^{2}$ - Thomas Stephen Ramsey ${ }^{2}$. \\ Huang Zhengwei ${ }^{1}$
}

Published online: 22 September 2018

(c) The Author(s) 2018

\begin{abstract}
This study investigates factors that affect customer satisfaction and the degree that service with an e-smile, service quality and customer mood affect consumer satisfaction. Data from 366 valid samples were obtained using an online survey. The research model is assessed using partial least squares analysis. The results show that customer satisfaction is predicted collectively by e-smile service, service quality and customer mood. Customer satisfaction with online service is predicted primarily by service quality, followed by customer mood and service with an e-smile. The results suggest that service with an e-smile provides considerable explanatory power for service quality and customer mood.
\end{abstract}

Keywords Social commerce context - E-smile service $\cdot$ Customer satisfaction · Service quality $\cdot$ Customer mood

\section{Introduction}

The popularity of social media opens new horizons for e-commerce. With social media as a business transaction service platform, the interaction between buyers and sellers is exerting a growing important influence on customers' purchase decision. Unlike conventional e-business, online customers communicate with sellers two-way other than just passively receiving messages from sellers in the context of social e-business. The new mode of bilateral online communication between buyers and sellers has become a significant way of conducting online business and serving customers for Chinese e-commerce enterprises [1-3]. Alfaro indicates that customers' purchase experience could be greatly ameliorated by virtue of social media technology which reinforces

\footnotetext{
$凶 \quad$ Huang Zhengwei zhengweihuang@ctgu.edu.cn

1 College of Economics and Management, China Three Gorges University, Yichang, China

2 School of Foreign Languages, China Three Gorges University, Yichang, China
} 
the interaction between buyers and sellers [4]. Kim and Park [5] have noted that social business has more social attributes since business based upon an online social media platform is conducted more often by single person than by conventional enterprise entity; the communication between potential customers and individual sellers is to a certain extent more frequent. Online communication is characterized with more information sharing and exchange and accordingly brings more unique purchase experiences for customers. Hajli [6] proposes that social media provides users with both tools and context for internet communication, which enables customers to start spontaneous dialogue with sellers involving diverse topics, contents and various participants. Sellers share information with interested customers and direct them to the purchase links they provide, which in turn brings more passive consumption of merchandise.

With the rapid development of domestic e-commerce, commercial instant messaging software has been rapidly popularized and applied in e-commerce enterprises. The main e-commerce companies use online customer service as the main channel for visitors to the Web site. The use of the Internet to achieve product sales (or to get orders) belongs to the category of e-commerce, and the use of the Internet for publicity and promotion is the vocation of network marketing, and online customer service is the basis for the realization of many network marketing effects. Therefore, strengthening interaction between customers and sellers highlights the significance of online customer service in the context of social business.

In social business, online customer service workers are serving in front of virtual windows when interacting with customers, the service quality of whom will be quite influential for customers' purchase decisions and experience. As for customers, they break free from time and space constraints; as for the enterprises, online service can effectively cut down the service cost and consequently bring in competitive advantages. Accordingly, online customer service systems play important roles not only as an essential tool to respond to customers' quests but also as an important means through which the interaction between customers and sellers is enhanced and the management of customer service in the context of social business is made accessible [7-11, 12, 13].

Customer service has developed from face-to-face counter-standby service, call center service to today's online customer service in forms of diversity [14]. Compared with predecessors, online customer service is a kind of typical intangible service that has advantages such as quick response, good interactivity and availability of one staff serving multiple customers [15]. As a typical contactless service, online customer service is primarily implemented through dialog, the function of which is at length fulfilled with text, voice and pictures as major carriers of information [16]. Nonetheless, in the new form of communication, there is a paucity of emotional demonstration traditionally conveyed by rich facial expressions, tones and gestures. Consequently, sellers resort to various emoticons such as "smiley" and "likes" and language with intimacy as an avenue to breaking the ice and building a friendly atmosphere when interacting with customers [17, 18-20].

There have been studies showcasing that positive emotions and facial expressions have a favorable influence on attitudes, preference and satisfaction of customers in the traditional tangible form of customer service [21]. Pugh has found that his bank worker, Pugh's research subjects, would induce more positive responses from customers if bankers display positive emotions (like smiles and greetings) [22]. Similarly, 
Daus [23] confirms that service staffs' emotions are associated with the customerperceived service quality. Brown and Sulzer-Azaroff [24] note that bank cashier's greeting language will prominently influence customers' satisfaction in the study of relationship between service staffs' emotional intelligence and customers' satisfaction index. Barger [25] thinks that service workers' smiles considered a sort of emotional labor could yield a contagious, emotional response between customers and service workers in the context of service encounter. Contrary to conventional service, customer service in social business scenarios is based on bilateral interaction in the form of text, in which the shortage of facial expression, tones and gestures would become a barrier to the service quality improvement [26]. The contactless textual interaction process between staffs and customers has become an important basis for influencing customers' evaluation of the entire service. Then, a problem arises henceforth: in the context of social business, is it possible to increase customer service quality by virtue of emoticons like smiley and likes, or just text?

Online customer service practice precedes theoretical exploration. The study of esmile service influences on customer service quality and customers' satisfaction makes sense in two aspects: firstly, the study can be used as a reference for enterprises to enhance the instance and interaction of customer service management; secondly, the study can be used as a framework to assess customer service workers' performance and a guide to help service workers to improve the service with emoticons and emotional text.

\section{Conceptual background}

\subsection{Service with an e-smile}

Smiles are very important facial expressions which convey positive emotions. When customers are contacting sellers, positive emotional interaction could provide customers the quality service beyond their expectation [27]. Research done by Barger and Grandey [25] displayed that emotion display, particularly smiles, will have positive influence on customer's satisfaction with service. However, influential factors in face-to-face service are not so applicable in a virtual context. So, historical literature in the study of customer service requires reinterpretation to suit the new social business context. E-smile service in the context of social business has its own unique excellence with emoticons to convey personal feelings and nonverbal information, hence bringing extraordinary purchase experience to customers.

In social business, e-smile service is defined as individualized customer service through digital language and nonverbal online emoticons in place of service workers' gestures and expressions to convey emotional information. Emoticons, special punctuation, delightful icons and particular selection of vocabulary bring more bilateral communication and a feeling of fashion, novelty, personalization to customers [28]. When service workers communicate with customers in social business, success of delivering positive emotion will be of vital importance in making a deal. With the help of friendly emoticons and text, service workers can make communication with customers more effectively and efficiently, which could greatly increase customers' 
satisfaction index. E-smile service conveys friendliness to customers, closing the gap between service workers and customers and reducing the estrangement brought by physical distance in the real world. In a word, e-smile service makes communication between service workers and customers more effective and smooth [29]. This study tested the quality of e-smile service in two aspects: degree of conveying a smile in text and smile categorization. Text is a reflection of how enthusiastic and friendly service workers are; smile emoticons are a mirror of how personalized the service is. Both could illustrate the nature of e-smile service and could be used as a framework in testing online customer service quality.

\subsection{Service quality}

From the perspective of cognitive psychology, customer service is involved in the psychology of comparing expectations and actuality. Service quality is an intangible experience which can be felt and evaluated from technical and functional angles [30]. The Internet era expands the conceptual realm of conventional service. The online service refers to all approaches people adopt to supply types of service for customers who could evaluate the service online [31]. Generally, content, procedure and effect could be used to assess service quality.

A through literature review of pertinent research defines service quality in the context of social business as evaluation and assessment of customer service. Zeithaml et al. [32] proposed measuring the quality of electronic services from seven factors which are efficiency, reliability, realization, privatization and response, compensation and relation. Electronic services are services provided over the Internet. They are managed by customers and are naturally interactive. Electronic services are available in the form of shopping websites, virtual communities, social networking sites, ebanking and other online media. Zeithaml pointed out that in order to promote repeat purchases and build customer loyalty, companies should shift their focus from electronic transactions to electronic services. Regarding the quality of electronic services, this article continues the view of service quality [33]. Based on e-SERVQUAL scale and the attributes of online customer service, four factors-efficiency, system reliability, realization and privatization - are used to test online customer service quality. Efficiency tests how fast workers respond to customers' requests; system reliability tests how fast customers could access online service windows and how helpful online customer service system is; realization tests whether customers' requests like delivery address problem are properly answered and tackled; privatization tests whether workers can keep secret of customers' personal and transaction information such as order information, payment information and chatting information.

\subsection{Customer mood}

Customers' mood refers to feelings like happiness, excitement and thrill occurring in the process of being served by service workers [34]. Feelings will affect customer's perception of the service received, which can be exploited to test whether customers' demands are met. With more understanding of human's mood, some researchers bring 
it up that purchase experience is in essence an experience of mood, which spotlights customers' feelings as a core element to assess service quality [35]. In social business, e-smile service could bring better experience to customers and motivate customers to have favorable evaluation of service.

Customers' mood has been described in either two dimensions or three dimensions. Russell and Pratt have proposed two dimensions of pleasure and arousal, while Waston and Tellegen have put forward another two dimensions of positive mood and negative mood, both of which are well accepted by the academic community [36, 37]. Three dimensions' proposal originated from a study done by Mehrabian and Russell who consider pleasure, arousal and dominance as major factors to observe [38]. Regarding the unique communication procedure and attributes of social business, this study will test in terms of two dimensions, pleasure and arousal [39]. It is such designed because the two dimensions' model could more accurately depict and distinguish customers' moods when communication between service workers and customers is more frequent. In this study, pleasure is the feeling like happiness customers feel when being served online; arousal is the feeling like the thrill and excitement customers feel when being served online.

\subsection{Customer satisfaction}

Since the late 1990s, customer satisfaction management was a fad in both the industrial and academic worlds, product standardization upgraded from "zero defect" to "thorough customer satisfaction". Customer satisfaction could be comprehended in two approaches: one defines satisfaction by feelings like pleasure or disappointment customers feel after comparing expected service with actual service. When actual service exceeds expectation, customers feel happy and content [40]. The other defines customers' satisfaction as a psychological response after their demands are met, a judgment of how well the products or service meet their demands [41]. Both approaches incorporate customers' cognition and emotion involved in making judgments. Cognition refers to the judgment customers make when contrasting performance of products or service with certain default criteria, whereas emotion refers to psychological behaviors like pleasure, surprise and fury when their demands are met or not [37].

Abundant accomplishments have been achieved in the research of customers' satisfaction in either a web or conventional face-to-face environment. Based on research of predecessors, this study focuses on factors that influence customers' satisfaction in social business and on evaluation from customers as well. In social business, customers' satisfaction reflects customers' psychological happiness and content when their demands are met or a state of pleasure when customers' expectation is met. Szymanski [42] thinks customers' satisfaction is an overall perception of product and service consumption in social business. Satisfaction, perceived during the whole process of transaction, means customers are content and happy after finishing a transaction and receiving a certain kind of service. Related studies are primarily about factors that are proven to affect customers' satisfaction index in different industries. Based on research concerning interaction features of social business and factors that influence customer satisfaction such as techniques service workers employ, gap between cus- 
tomers' expectation and actuality, service quality, this study focuses on influence of e-smile service, service quality and customer mood on customer satisfaction.

\section{Research model and hypothesis}

(1) E-smile has a straightforward influence on customers' satisfaction.

In customer service, "e-smile" has been regarded as mandatory for worders as it helps to increase customers' willingness and satisfaction in making a deal [24, 43]. Related research has shown that smiling service in face-to-face context will affect customers' attitudes and behaviors. Rafaeli and Sutton [44] note in their research that smiles on service workers' faces, regardless of sincerity or not, will make customers happy. Tsai and Huang [45] find that smiling service workers will improve customers' experience. Barger and Grandey [25] indicate that emotion exposure, especially smiling behavior, positively influences customers' satisfaction.

Different from off-line service, Derks and Fischer [46] think that mood is hard for service workers to display in an online service context, particularly in the condition of communicating with strangers (often happens between service workers and customers). However, Ishii and Markman [47] consider appropriately exposing emotion is of superb importance for online service workers. Though Darley [48] points it out that factors influencing customers' satisfaction in off-line condition does not suit online context, Huang and Yen's [29] study demonstrates that the use of emoticons in online interaction could help service workers to convey personal feelings to customers and to increase the intensity of text message expression, consequently making individualized service possible. Moreover, studies completed by Lii and Chien [49] indicate that online service workers have to be more engaged than their off-line counterparts. In terms of existent literature, this study proposes hypothesis as below:

H1 e-smile service has positive effect on customers' satisfaction.

(2) Hypothesis of e-smile service's quality influencing customers' satisfaction

E-smile service is an explicit visual signal, whether in the form of text or emoticons, and will bring changes to customers' psychology. In conventional context, researchers have found that there exists a mediating relationship between service workers' smiles and customers' satisfaction by research utilizing empirical methodology like structural equation modeling. Brown and Sulzer-Azaroff [24] find that service workers' smile is implicitly related to customers' satisfaction, and the service staff smile does contribute to customer satisfaction, but the path of the service affecting customer satisfaction also needs to consider other mediating variables. Barger and Grandey [25] point out that customers' perception of service quality is mediating between smiling behaviors and customers' satisfaction.

Related studies show that perceived service is positively correlated with customers' satisfaction in an online business context [50]. For online service, customers' evaluation is primarily based upon factors of effect and procedure, both of which will decide the fulfillment of customers' expectation and obtainment of delightful consumption experience. When service workers communicate with customers online, smiles will 
affect customers' cognitive evaluation of service. To be more specific, the staffs' smile service influences customer satisfaction by affecting the evaluation of service quality. High-rating service predicts how content customers feel about the service, and online customer service with an e-smile can improve customer satisfaction by improving customer service quality [49]. In light of the above studies, this study proposes hypothesis as below:

H2 e-smile service has positive effect on service quality.

H3 service quality has positive effect on customers' satisfaction.

(3) Hypothesis on e-smile service having implicit impact on customers' satisfaction through its influence on customer mood.

Based on emotional contagion and emotional labor theory, smiling expressions cause emotional infections between customers and customer service personnel, which are the key factors that determine the overall feelings of customers and the final evaluation. In social business, online service makes it impossible for customer service workers to communicate with customers face-to-face verbally and visually, leaving customers to make decision upon information they receive online. E-smile service has been considered important in assessing online service quality with real-time communication tools. In light of emotional contagion and emotional labor theory, Henning and Groth [51] put it forward that the effect of service workers' emotion influencing customers could be achieved by two vital variables: service workers' smile extent and friendliness. Watson and Tellegen's [37] research indicates that customer's likelihood of imitating service workers' expressions to alter their own mood increases when service workers show more smiles. In addition, Söderlund and Rosengren [52] propose a model, presenting a relationship between smiles and satisfaction through two mechanisms: one is emotional contagion which means one will capture mood displayed by his counterpart; the other is emotional penetration which refers to the ability to induce emotions by a specific object. Those two mechanisms have been proven to be positively influential on customers' satisfaction.

In the current research, it has been both empirically and theoretically confirmed that customer mood has a significant influence on satisfaction. Liljander and Strandvik [35] demonstrate that customers' moods have straightforward influence on satisfaction, and negative moods are considered to be more powerful than positive. Dube's [53] research targeting medical service illustrates that positive mood has a positive effect, whereas negative mood doesn't always lead to dissatisfaction. Oliver [41] categorizes negative emotions into ones triggered by other people, ones brought by the environment and ones incurred by personal experience. Based on Oliver's categorization, Dube and Menon [54] have proven that only negative moods incurred by others (service providers) will lead to dissatisfaction. Furthermore, negative moods initiated by others will reduce customers' perception of subsequent service performance. Ladhari [55] displays in his research that evoking emotions positively affects pleasant emotions, pleasant and arousing emotions positively affect customer satisfaction, and pleasant emotions have greater influence on customer satisfaction than arouse emotions. Customers evaluate the provided service's quality via mood they experience in 


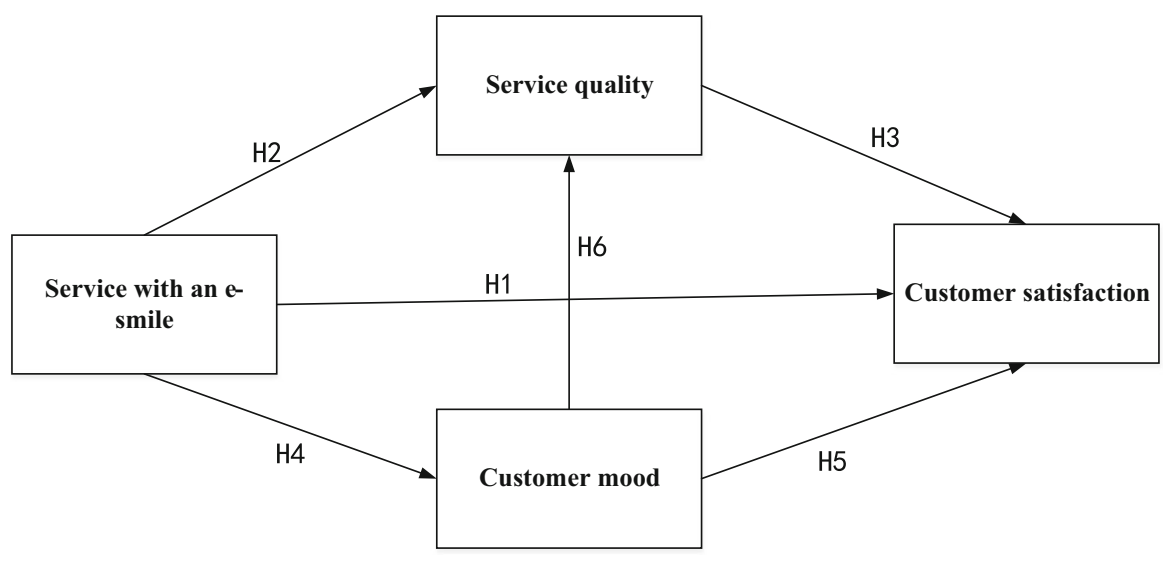

Fig. 1 Research model

communicating with service workers [56]. Hwab's [57] study considers that in the process of communicating with customers, service workers' good relationship with customers will make communication outcomes more predictable and controllable and help to avoid unexpected situations to improve service quality.

Perceived service quality is a process of cognitive judgment and evaluation of services. Since moods could influence cognitive decision, mood is supposed to have influence on customer-perceived service quality. Conventionally service workers could try all strategies to boost emotional contagion with customers, while online service has disadvantages both visually and verbally, particularly in terms of lacking facial expression and gestures. Paucity in sensual images makes the communication just in form of text hard to understand. Sometimes, misunderstanding arises with text communication alone. In a word, distant mood communication via text and emoticons makes communication more subject to customers-perceived service quality.

H4 e-smile service has positive effect on customers' moods.

H5 customers' moods have positive effect on customers' satisfaction.

H6 customers' moods have positive effects on service quality.

In the traditional service field, more mature models have been formed around service quality, customer sentiment and customer satisfaction, such as expectation-confirmation model and customer satisfaction index model, which constitute the core theory and method of customer relationship management. However, for e-smile service, scholars have not clearly stated their status and role, nor have they tested the relationship between quality and customer sentiment and customer satisfaction. Based on theories proposed as above, this study establishes a model of e-smile service on customers' satisfaction in social business context after analysis of e-smile service features and exploration of related studies. In summary, see Fig. 1 for a representation of the proposed links. 


\section{Research methodology}

\subsection{Data collection and subjects}

The subjects of this research were individuals who had experience using online customer service. We released the questionnaire on a special survey Chinese website "Star Questionnaires" which is operated by Shanghai Circulating Information Technology Co., Ltd., and put the survey's hyperlink on QQ, WeChat and Weibo. Participants can answer the questionnaire directly into the page by clicking a hyperlink. We define that each computer or IP address can only answer one questionnaire to ensure that each questionnaire is finished by one independent person. We also give participating respondents a certain reward through the website platform. The platform provided one small gift to ten winners randomly chosen from the survey respondents, in order to attract individuals to fill out our questionnaire. According to the statistical data on the website, a total of 450 people participated in the survey. But there were 84 people who chose never used online customer service and then skip to the end of the questionnaire submitted to it, so the response rate is $81.3 \%$ (366/450, 366 effective questionnaires).

\subsection{Measurement development}

The following four constructs were measured using multiple-item scales: service with an e-smile, service quality, customer emotion and customer satisfaction. We adopted a definition from previous studies and then modified the questions to the context of online customer service. Applicability of the modified items was enhanced by literature reviews, and a pretest to ensure content validity. Before the data collection, we first consulted experts in related fields for the questionnaires and then conducted pre-study on 20 research subjects. They were asked to comment on the items reflecting the constructs, semantic wording, length and format of the questionnaire. The questionnaire was revised based on their feedback to ensure the validity of the questionnaire. The scale of perceived online customer service quality and its influence factors is designed with 5 -point Likert scale $(1=$ strongly disagree; $2=$ disagree; $3=$ neither agree nor disagree; $4=$ agree; and $5=$ strongly agree).

\section{Data analysis and results}

\subsection{Descriptive statistics}

A total of 366 respondents were surveyed online. Of these 366 participants, 233 were women (63.6\%) and 133 were men (36.4\%). The majority of respondents were aged between 21 and $30(80.9 \%)$ and had postsecondary education (90. 2\%). The most recent online service experience for the majority of respondents was within a year, and they had engaged in online customer service at least three times (61.7\%). Table 1 shows the respondent demographics. 
Table 1 Descriptive statistics of respondents' characteristics $(N=366)$

\begin{tabular}{llrr}
\hline Measure & Items & Frequency & Percent \\
\hline Gender & Male & 133 & 36.4 \\
& Female & 233 & 63.6 \\
Age & $<20$ years old & 42 & 11.5 \\
& $21-30$ years old & 296 & 80.9 \\
& $31-40$ years old & 19 & 5.2 \\
Education & $>41$ years old & 9 & 2.4 \\
& High school (below) & 36 & 9.8 \\
Frequency of using online & College & 225 & 61.5 \\
customer service within a year & Master (above) & 105 & 28.7 \\
& $<3$ times & 140 & 38.3 \\
\hline
\end{tabular}

\subsection{Measurement model}

The measurement model was assessed by using the partial least squares (PLS) method. It is an appropriate analytical tool in this case because it has minimal demands on measurement scales, sample size and residual distributions [58]. This study employs the structural equation modeling tool SmartPLS (version 3.2.6) for confirmation factor analysis to estimate the measurement model using PLS analysis to test construct reliability and validity. Composite reliability represents the internal consistency of the measurement model. The results in Table 2 show the factor loading of all items exceeds $0.5[59,60]$ and are significant $(p<0.01)$. Composite reliabilities ranged from 0.87 to 0.95 , all exceeding 0.7 [61], and the AVE of each construct ranged from 0.69 to 0.83 , all exceeding $0.5[58,62]$. Table 2 shows that all indices fit with heuristics.

Discriminate validity is tested in the measurement model analysis to determine the correlations between the latent variables and other constructs. The convergent and discriminant validity were assessed by checking whether the AVE (average variance extracted) of each construct is larger than its correlation with the other constructs and whether each item had a higher loading on its assigned construct than on the other constructs $[62,63,64]$. The results indicate that the discriminate validity was achieved, as shown in Table 3.

\subsection{Structure model}

Based on the confirmed reliability and validity analysis of the measurement model, the research model was assessed using PLS. The bootstrap method was applied to determine the significance of the structural model paths. The path coefficient and significance of each hypothesis were examined. The explained variance (R2) of each dependent construct was calculated. Figure 2 shows the standardized path coefficient and the significance of each path, reported by SmartPLS 3.2.6. 
Table 2 Scale properties of measurement model

\begin{tabular}{lllllr}
\hline Construct & Item & Item mean & $\begin{array}{l}\text { Standard } \\
\text { deviation }\end{array}$ & $\begin{array}{l}\text { Standardized } \\
\text { item loading }\end{array}$ & $T$ statistic \\
\hline ES & ES1 & 2.689 & 0.564 & 0.740 & 1.875 \\
SQ & ES2 & 2.697 & 0.581 & 0.995 & 5.263 \\
& SQ1 & 3.579 & 0.828 & 0.714 & 11.113 \\
& SQ2 & 3.279 & 0.937 & 0.702 & 20.779 \\
& SQ3 & 3.333 & 0.877 & 0.783 & 31.822 \\
& SQ4 & 3.787 & 0.795 & 0.720 & 6.044 \\
& SQ5 & 3.699 & 0.791 & 0.784 & 16.500 \\
& SQ6 & 3.607 & 0.745 & 0.804 & 36.119 \\
& SQ7 & 3.751 & 0.698 & 0.742 & 23.822 \\
CM & SQ8 & 3.068 & 0.904 & 0.770 & 15.937 \\
& SQ9 & 3.107 & 0.844 & 0.714 & 12.539 \\
& CM1 & 2.792 & 0.856 & 0.862 & 22.247 \\
& CM2 & 3.123 & 0.883 & 0.892 & 46.308 \\
& CM3 & 2.716 & 0.807 & 0.726 & 0.592 \\
CS & CM4 & 2.669 & 0.808 & 0.758 & 0.265 \\
& CS1 & 3.680 & 0.689 & 0.830 & 37.067 \\
& CS2 & 3.784 & 0.657 & 0.770 & 16.684 \\
& CS3 & 3.093 & 0.787 & 0.767 & 13.684 \\
& CS4 & 3.809 & 0.615 & 0.734 & 15.506 \\
\hline
\end{tabular}

Table 3 Scale properties and correlations

\begin{tabular}{|c|c|c|c|c|c|c|c|}
\hline \multirow[t]{2}{*}{ Construct } & \multirow{2}{*}{$\begin{array}{l}\text { Cronbach's } \\
\text { alpha }\end{array}$} & \multirow[t]{2}{*}{ Reliability } & \multirow[t]{2}{*}{ AVE } & \multicolumn{4}{|c|}{ Factor correlations } \\
\hline & & & & ES & SQ & $\mathrm{CM}$ & CS \\
\hline ES & 0.720 & 0.817 & 0.700 & 0.837 & & & \\
\hline SQ & 0.849 & 0.882 & 0.561 & 0.129 & 0.679 & & \\
\hline $\mathrm{CM}$ & 0.701 & 0.706 & 0.503 & 0.144 & 0.590 & 0.624 & \\
\hline CS & 0.743 & 0.838 & 0.566 & 0.713 & 0.666 & 0.557 & 0.752 \\
\hline
\end{tabular}

As Fig. 2 demonstrates, research analysis explained 62.5 percent of the variance in customer satisfaction. $\mathrm{H} 1, \mathrm{H} 3$ and $\mathrm{H} 5$ examined the effect of three factors to customer satisfaction. Service with an e-smile $(\beta=0.297, * p<0.05)$, service quality $(\beta=$ $\left.0.502,{ }^{* * *} p<0.001\right)$ and customer $\operatorname{mood}\left(\beta=0.257,{ }^{* * *} p<0.001\right)$ were positively associated with customer satisfaction. Moreover, the research analysis explained 35.8 percent of the variance in service quality and 49.4 percent of the variance in customer mood. Success to find support for $\mathrm{H} 2$ indicated that service with an e-smile had a significant positive association with service quality $\left(\beta=0.344,{ }^{*} p<0.05\right)$. Service with an e-smile had a very significant influence on customer mood $\left(\beta=0.403\right.$, $\left.{ }^{*} p<0.05\right)$, positively supporting $\mathrm{H} 4$. H6 examines the effects of customer mood on service quality. 


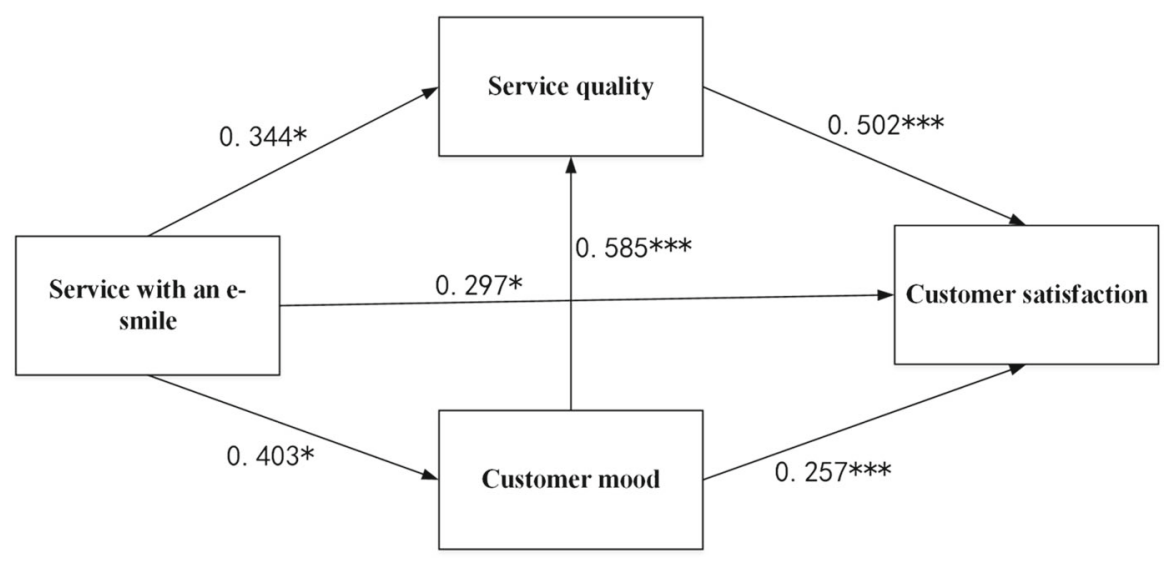

Fig. 2 Results of structure model

Customer mood was significantly related to service quality $\left(\beta=0.585,{ }^{* * *} p<\right.$ $0.001)$.

\section{Discussion}

In this study, a model about factors of e-smile service influencing customer satisfaction in a social business context is built. Results show that there is a positive correlation between e-smile service and customer satisfaction. It implies that e-smile service of online customer service workers helps to alleviate the communication atmosphere in social business context. Furthermore, the study showcases that smiles do have influence on service quality. In the context of social business, online service will exert a positive effect on customers with friendly text and smiling emoticons, which does enhance customers' satisfaction.

E-smile service has a significant influence on service quality by affecting customer mood. In social business context, e-smile service is conducted with agreeable words, text and smiling emoticons to convey happiness to customers with an intention of cheering up customers during communication and to generate delightful feelings in customers. The employment of friendly text and smiling emoticons not only closes the psychological gap between customer service workers and customers but also resolves embarrassment and awkwardness brought by misunderstanding. This helps to make communication smooth and customers to feel more relaxed. This in turn improves the online service quality.

The study results also display e-smile service has a significant influence on customers' satisfaction via two mediators - service quality and customers' mood. Compared with service quality, e-smile service is more ostensibly influential on customers' mood. Service workers' attitudes can be perceived by customers by the use of e-smile service with text and emoticons. In the process of communicating with service workers, customers will evaluate service quality through service workers' service techniques, attitudes, behaviors and service facilities, device and environment, which 
explains why e-smile service is not as influential on service quality as on customer mood. In social business, service workers convey friendliness to customers and induce positive mood from customers primarily through smiling emoticons and delightful text and solve customers' problems beyond their expectation, which in the end reinforce the good impression on customers' minds and increase customers' satisfaction.

\section{Conclusion}

This study explores the influence of e-smile service, customers' mood and service quality on customers' satisfaction. The results show that service quality and customers' mood can be the most powerful factors to predict customers' satisfaction, with e-smile service factor ranking next. There exists a positive correlation among e-smile service, customers' mood and service quality, though e-smile service is proved to be the most influential. Therefore, it is suggested that customer service workers should improve service techniques with e-smile signals on social media platforms when communicating with customers so that customers can feel the friendliness and positive attitudes from service workers. This could generate a positive mood from customers, improve online service quality and increase customers' satisfaction.

Online customer service has good interactivity and communication efficiency compared with email and phone. Online customer service is an excellent product that makes traffic flow into sales, taps potential customers and improves sales. Online customer service plays an important role in providing e-commerce companies with "just-in-time" information consulting services and also strengthens communication between enterprises and customers, which greatly enhances customer service satisfaction. Therefore, this paper is based on the research of e-smile service, which is of great significance to marketing and corporate decision making.

We encourage further studies in the future to come while confirming the influence of e-smile service on customers' satisfaction in social business context. Here are some proposals: firstly, application of empirical studies to more industries is quite alike since this study is mainly confined to e-commerce. In the days to come, e-smile service could be extended to other industries like banking industry, which will expand sample size and make the study results more convincing and practical; secondly, the model of e-smile service on customers' satisfaction needs further refinement. Taking other mediators into account, improving and refining the established model, further exploration of factors that might influence e-smile service, considering postvariables like customers' willingness of making a second purchase, is left for future studies. After all, this study is only confined to e-smile service in the context of social business, and future work is urgently required for more innovative ways of serving customers online.

Acknowledgements This paper is under Grant of National Natural Science Foundation of China (No. 71471102).

Open Access This article is distributed under the terms of the Creative Commons Attribution 4.0 International License (http://creativecommons.org/licenses/by/4.0/), which permits unrestricted use, distribution, and reproduction in any medium, provided you give appropriate credit to the original author(s) and the source, provide a link to the Creative Commons license, and indicate if changes were made. 


\section{References}

1. Hajli MN (2014) The role of social support on relationship quality and social commerce. Technol Forecast Soc Chang 87(1):17-27

2. Stephen AT, Toubia O (2008) Deriving value from social commerce networks. J Mark Res 47(2):215-228

3. Chen YC, Wu JH, Peng L, Yeh RC (2015) Consumer benefit creation in online group buying: the social capital and platform synergy effect and the mediating role of participation. Electron Commer Res Appl 14(6):499-513

4. Alfaro E (2010) El abc del customer experience. Walters Kluver, España

5. Kim S, Park H (2013) Effects of various characteristics of social commerce (s-commerce) on consumers' trust and trust performance. Int J Inf Manage 33(2):318-332

6. Hajli N (2015) Social commerce constructs and consumer's intention to buy. Int J Inf Manage 35(2):183-191

7. Liang T, Ho Y, Li Y, Turban E (2011) What drives social commerce: the role of social support and relationship quality. Int J Electron Commer 16(2):69-90

8. Chen R (2013) Member use of social networking sites - an empirical examination. Decis Support Syst 54(3):1219-1227

9. Chen J, Shen XL (2015) Consumers' decisions in social commerce context. Decis Support Syst 79(C):55-64

10. Bianchi C, Andrews L, Wiese M, Fazalehasan S (2017) Consumer intentions to engage in s-commerce: a cross-national study. J Mark Manag 4:1-31

11. Pothong C, Sathitwiriyawong C (2017) Factors of s-commerce influencing trust and purchase intention. In: Computer Science and Engineering Conference (pp 1-5). IEEE

12. Liu H, Chen Y, Zha Y et al (2018) The effect of satisfaction on loyalty in consumption and service industry based on meta-analysis and it's algorithm. Wireless Pers Commun. https://doi.org/10.1007/s 11277-018-5489-8

13. Wang D, Liu J, Wang X et al (2017) Cost-effectiveness analysis and evaluation of a 'three-old' reconstruction project based on smart system. Cluster Comput. https://doi.org/10.1007/s10586-017-14903

14. Rose S, Hair N, Clark M (2011) Online customer experience: a review of the business-to-consumer online purchase context. Int J Manag Rev 13(1):24-39

15. Tseng JCR, Hwang GJ (2007) Development of an automatic customer service system on the internet. Electron Commer Res Appl 6(1):19-28

16. Qiu L, Benbasat I (2005) Online consumer trust and live help interfaces: the effects of text-to-speech voice and three-dimensional avatars. Int J Humanâ Comput Interact 19(1):75-94

17. Wang D, Zha Y, Bi G et al (2018) A meta-analysis of satisfaction-loyalty relationship in E-commerce: sample and measurement characteristics as moderators. Wireless Pers Commun. https://doi.org/10.10 07/s11277-018-5488-9

18. Wang D, Liu J, Chen Y (2018) Distinguishing investment changes in metro construction project based on a factor space algorithm. Cluster Comput. https://doi.org/10.1007/s10586-018-2164-5

19. Chen Y, Wang D, Bi G (2018) An image edge recognition approach based on multi-operator dynamic weight detection in virtual reality scenario. Cluster Comput. https://doi.org/10.1007/s10586-017-160 4-y

20. Wang D, Chen Y, Chen, D (2018) Efficiency optimization and simulation to manufacturing and service systems based on manufacturing technology Just-In-Time. Pers Ubiquit Comput (2018). https://doi.o $\mathrm{rg} / 10.1007 / \mathrm{s} 00779-018-1161-2$

21. Menon K, Dubé L (2000) Ensuring greater satisfaction by engineering salesperson response to customer emotions. J Retail 76(3):285-307

22. Pugh SD (2001) Service with a smile: emotional contagion in the service encounter. Acad Manag J 44(5):1018-1027

23. Daus CS (2001) Rater mood and employee emotional expression in a customer service scenario: interactions and implications for performance review outcomes. J Qual Manag 6(2):349-370

24. Brown CS, Sulzer-Azaroff B (1994) An assessment of the relationship between customer satisfaction and service friendliness. J Organ Behav Manag 14(2):55-76

25. Barger PB, Grandey AA (2006) Service with a smile and encounter satisfaction: emotional contagion and appraisal mechanisms. Acad Manag J 49(6):1229-1238 
26. Turel O, Connelly CE, Fisk GM (2011) Service with an e-smile: employee authenticity and customer usage of web-based services. Inf Manag 50(2-3):98-104

27. Turel O, Connelly CE, Fisk GM (2013) Service with an e-smile: employee authenticity and customer use of web-based support services. Inf Manag 50(2-3):98-104

28. Kress G (2001) Sociolinguistics and social semiotics. In: Cobey P (ed) The Routledge companion to semiotics and linguistics. Routledge, NewYork, pp 66-82

29. Huang AH, Yen DC, Zhang X (2008) Exploring the potential effects of emoticons. Inf Manag 45(7):466-473

30. Gronroos C (1990) Relationship approach to marketing in service contexts: the marketing and organizational behavior interface. J Bus Res 20(1):3-11

31. Santos J (2003) E-service quality: a model of virtual service quality dimensions. J Serv Theory Pract 13(3):233-246

32. Zeithaml VA, Parasuraman A, Malhotra A (2000) E-service quality: definition, dimensions and conceptual model. Marketing Science Institute, Cambridge

33. Zeithaml VA, Parasuraman A, Malhotra A (2002) Service quality delivery through web sites: a critical review of extant knowledge. J Acad Mark Sci 30(4):362

34. Campos J (1983) Socio-emotional development. In: Mussen P (ed) Handbook of child development. Wiley, Hoboken

35. Liljander V, Strandvik T (1997) Emotions in service satisfaction. Int J Serv Ind Manag 8(2):148-169

36. Russell JA, Pratt G (1980) A description of the affective quality attributed to environments. J Pers Soc Psychol 38(2):311-322

37. Watson D, Tellegen A (1985) Toward a consensual structure of mood. Psychol Bull 98(2):219

38. Mehrabian A, Russell JA (1974) An approach to environmental psychology. MIT, Cambridge

39. Havlena WJ, Holbrook MB (1986) The varieties of consumption experience: comparing two typologies of emotion in consumer behavior. J Consum Res 13(3):394-404

40. Oliver RL (1980) A cognitive model of the antecedents and consequences of satisfaction decisions. J Mark Res 17(4):460-469

41. Oliver RL, Rust RT, Varki S (1997) Customer delight: foundations, findings, and managerial insight 次. J Retail 73(3):311-336

42. Szymanski DM, Hise RT (2000) E-satisfaction: an initial examination. J Retail 76(3):309-322

43. Tsai WC (2001) Determinants and consequences of employee displayed positive emotions. J Manag 27(4):497-512

44. Rafaeli A, Sutton RI (1990) Busy stores and demanding customers: how do they affect the display of positive emotion? Acad Manag J 33(3):623-637

45. Tsai WC, Huang YM (2002) Mechanisms linking employee affective delivery and customer behavioral intentions. J Appl Psychol 87(5):1001-1008

46. Derks D, Fischer AH, Bos AER (2008) The role of emotion in computer-mediated communication: a review. Comput Hum Behav 24(3):766-785

47. Ishii K, Markman KM (2016) Online customer service and emotional labor: an exploratory study. Comput Hum Behav 62:658-665

48. Darley WK (2010) Guest editorial: the interaction of online technology on the consumer shopping experience. Psychol Mark 27(2):91-93

49. Lii YS, Chien CS, Pant A, Lee M (2013) The challenges of long-distance relationships: the effects of psychological distance between service provider and consumer on the efforts to recover from service failure. J Appl Soc Psychol 43(6):1121-1135

50. Izogo EE, Ogba IE (2015) Service quality, customer satisfaction and loyalty in automobile repair services sector. Int J Qual Reliab Manag 32(3):250-269

51. Hennigthurau T, Groth M, Paul M, Gremler DD (2006) Are all smiles created equal? How emotional contagion and emotional labor affect service relationships. J Mark 70(3):58-73

52. Sönderlund M, Rosengren S (2004) Dismantling "positive affect" and its effects on customer satisfaction: an empirical examination of customer joy in a service encounter. J Consum Satisf Dissatisf Complain Behav 17:27

53. Dubé L, Bélanger MC, Trudeau E (1996) The role of emotions in health care satisfaction. positive feelings have the expected effect, but negative ones do not always result in dissatisfaction. J Health Care 16(2):45

54. Dubé L, Menon K (2000) Multiple roles of consumption emotions in post-purchase satisfaction with extended service transactions. Int J Serv Ind Manag 11(3):287-304 
55. Ladhari R (2007) The effect of consumption emotions on satisfaction and word-of-mouth communications. Psychol Mark 24(12):1085-1108

56. Rafaeli A, Sutton RI (1989) The expression of emotion in organizational life. Res Organ Behav 11(4):1-42

57. Hwa AMC, Thurasamy R, Wafa SA (2010) Exploring the dimensionality of emotional labor: the case of the Malaysian Hospitality Industry. Int J Bus Res 10:1

58. Chin W, Marcolin B, Newsted P (1996) A partial least squares latent variable modeling approach for measuring interaction effects: results from a monte carlo simulation study and voice mail emotion/adoption study. Paper Presented at the 15th International Conference on Information Systems (pp 21-41). Cleveland, Ohio, USA

59. Nunnally J (1978) Psychometric methods, 2nd edn. McGraw-Hill, New York

60. Wixom B, Watson H (2001) An empirical investigation of the factors affecting data warehousing success. MIS Q 25(1):17-41

61. Bagozzi RP, Yi Y (1988) On the evaluation of structural equation models. J Acad Mark Sci 16(1):74-94

62. Fornell C, Larcker D (1981) Evaluating structural equation models with unobservable variables, and measurement error. J Mark Res 18(1):39-50

63. Gefen D, Straub D, Boudreau M (2000) Structural equation modeling techniques and regression: guidelines for research practice. Commun AIS 7(7):1-78

64. Wang D, Chen Y, Xu J (2017). Knowledge management of web financial reporting in human-computer interactive perspective. Eurasia J Math Sci Tech Ed 13(7):3349-3373. https://doi.org/10.12973/eurasi a.2017.00733a 